\title{
Alternative Medicine for Treating Depression
}

\section{Susheelkumar V Ronad*1, Chetan S Patali ${ }^{2}$, Shridhar H Gondbal ${ }^{3}$, Kirankumar TC ${ }^{4}$, Mallikarjuna Ronad ${ }^{5}$, Pankaja TC $^{6}$, Rajendra Badesgol ${ }^{7}$, Peekesh kumar J Singhal ${ }^{8}$ and Bhalvinder Kaur ${ }^{9}$}

${ }^{1}$ Lecturer, Department of Psychiatric Nursing DIMHANS Dharwad, India

${ }^{2}$ Principal, Dhanush institute of Nursing Sciences Bagaklot

${ }^{3}$ Staff Nurse, Indira Gandhi Children's Hospital, india

${ }^{4}$ Assistant Professor, Department of Management Studies, Karnataka Arts College, India

${ }^{5}$ Civil Engineering Student, MSRUAS Bangalore

${ }^{6}$ Assistant Professor, RL Law College, Davangere, India

${ }^{7}$ Department of Police, Belgaum

${ }^{8}$ HOD of Psychiatric Nursing, Institute of Medical Technology and Nursing Education, India

${ }^{9}$ Guide, Himalayas University, Itanager, India

Received: May 30, 2018; Published: June 07, 2018

*Corresponding author: Susheelkumar V Ronad, Lecturer, Department of Psychiatric Nursing DIMHANS Dharwad, Karnataka, India

Keywords: Depression; Exercise; Yoga; Massage; Meditation; Acupuncture

\section{Short Communication}

Alternative therapy for depression encompasses a variety of disciplines that includes everything from diet and exercise to mental conditioning and lifestyle changes.

\section{What is Integrative Therapy?}

A health treatment that is not classified as standard Western medical practice is referred to as "alternative," or "complementary" or "integrative." Integrative therapy encompasses a variety of disciplines that includes everything from diet and exercise to mental conditioning and lifestyle changes. Examples of integrative therapies include acupuncture, guided imagery, chiropractic treatments, yoga, hypnosis, biofeedback, aromatherapy, relaxation, herbal remedies, massage and many others.

There is some evidence that holistic treatment is effective for depression. Using holistic psychotherapies can help patients go back to the source of the depression in their lives and learn effective ways of using tools to manage the symptoms and in many cases improve their overall functioning.

\section{What are Some Integrative Therapies Used to Treat De- pression?}

Herbal Remedies: Before recommending any substance to treat reported depression or mood imbalance, providers will take detailed medical history to look for biochemical causes that may contribute to mood imbalance. The blood tests may check levels of certain substances, such as Vitamin D and folate, which may play a role in mood imbalance.

Acupuncture: Acupuncture is an ancient Chinese method of healing that prevents and cures specific diseases and conditions by sticking very fine, solid needles into specific points on the body. Acupuncture stimulates the body's ability to resist or overcome illness by correcting imbalances. It also prompts the body to produce chemicals that decrease or eliminate painful sensations.

In a recent clinical study, acupuncture has been shown effective in decreasing depression at three months, compared to usual care. For people who suffer from both pain and depression, acupuncture is better than counseling and standard of care at reducing both symptoms. Acupuncture is highly effective at treating pain, such as headaches; menstrual cramps; and low back, neck, or muscle pain. It also can be used to treat menopausal symptoms, allergy symptoms, and side effects due to radiation and chemotherapy.

Reflexology: Reflexologists believe that the body has the capacity to heal itself. The nerves in the hands and feet are related to various parts of the body. Reflexologists believe that the healing process is stimulated by applying pressure to specific points on the hands and feet. 
Exercise: Different forms of exercise can lower your stress; reduce depression; and increase your energy level, balance, flexibility, and ability to relax. In general, exercise is a safe and easy way to improve your well-being, but always check with your doctor before starting a new exercise program.

Meditation: Meditation is sometimes described as an altered state of consciousness. It is a form of relaxation that, unlike sleep, is entered into purposely. Meditation is usually practiced regularly-for at least 10 minutes each day. While the body is at rest, the mind is cleared by focusing on one thought, which could be a word, phrase, or particular scenery.

Massage: Massage uses touch to promote relaxation while decreasing tension and stress. The release of serotonin and dopamine, and the decrease of cortisol during a massage may help improve the symptoms of depression, lessen pain and improve sleep. Massage supports the mind-body connection, allowing for a better awareness of what is happening in our bodies. Some variations of massage that can support the mind-body connection and general relaxation are Swedish massage techniques, Reiki, aromatherapy, and craniosacral therapies.

Guided Imagery and Relaxation: Guided imagery is a form of focused relaxation that helps create harmony between the mind and body. Guided imagery coaches you in creating calm, peaceful images in your mind-a "mental escape" for therapeutic purposes. It can be a powerful psychological strategy to enhance a person's coping skills. It can help people cope with-and possibly overcome-stress, anger, pain, depression, and insomnia with or without associated physical illness.

Yoga: Yoga "meets you where you are," even when you are depressed. Practicing yoga teaches you breathing techniques that can help to energize you when you are feeling down or to help calm you at the times you may be feeling anxiety. The breath is the link between your mind and your body. Changing your breath can help you feel better mentally and physically. The postures and movements in yoga teach you how to hold your body in a way that can make you feel stronger, better able to breathe and function, and to create an improved sense of overall well-being.

\section{References}

1. MacPherson H, Richmond S, Bland M, Brealey S, Gabe R, et al. (2013) Acupuncture and Counselling for Depression in Primary Care: A Randomised Controlled Trial. PLoS Med 10(9): e1001518.

2. Hopton A, MacPherson H, Keding A, S Morley (2014) Acupuncture, counseling or usual care for depression and comorbid pain: secondary analysis of a randomised controlled trial. BMJ Open 4: e004964.

3. National Center for Complementary and Integrative Health.

4. Centers for Disease Control and Prevention - CDC Features: Meditation and Health.

5. Health Benefits of Yoga Explained: Yoga Health Foundation.

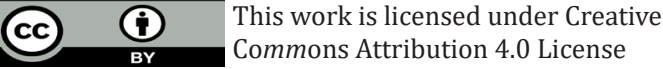

Submission Link: https://biomedres.us/submit-manuscript.php

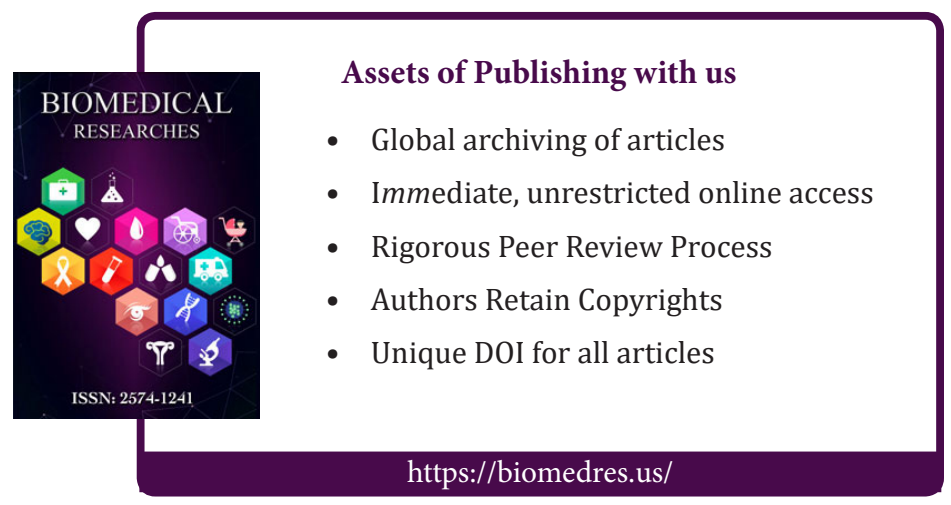

